\title{
WHO Community Engagement Package: A Reinforcement of an Inclusive Approach to Global Public Health
}

Semeeh Akinwale Omoleke ${ }^{1,2}$, Yolanda V. Bayugo ${ }^{1}$, Ukam Ebe Oyene ${ }^{1}$, Jonathan Abrahams ${ }^{3}$, Nina Gobat ${ }^{1}$, Suvajee Good ${ }^{4}$, Mary Manandhar ${ }^{5}$, Samar Elfeky ${ }^{6}$, Ana Gerlin Hernandez Bonilla $^{7}$, Nicole Valentine ${ }^{8}$, Jackeline Alger ${ }^{9}$, Qudsia Huda ${ }^{3}$, Saqif Mustafa ${ }^{10}$, Maria Isabel Echavarria ${ }^{11,12}$, Ankur Rakesh ${ }^{3}$, Taylor Warren ${ }^{3}$, Jostacio Moreno Lapitan ${ }^{3}$, Jana Deborah MierAlpano ${ }^{13}$, Dayo Spencer-Walters ${ }^{1}$, Meredith Del Pilar Labarda ${ }^{14}$, Mihai Mihut ${ }^{7}$, Aphaluck Bhatiasevi ${ }^{1}$, Obinna I. Ekwunife ${ }^{15}$

1. Country Readiness and Strengthening Department, Health Emergencies Programme, World Health Organization, Geneva, Switzerland

2. Field Presence Cluster, World Health Organization, Abuja, Nigeria

3. Health Security and Preparedness, WHO Health Emergencies Programme, World Health Organization, Lyon Office, France

4. Department of Healthier Populations and Non-Communicable Diseases, Regional Office for South-East Asia (SEARO), World Health Organization, New Delhi, India.

5. Department of Social Determinants of Health, World Health Organization, Geneva, Switzerland

6. Department of Healthier Populations, World Health Organization, Regional Office of Eastern Mediterranean Region, Cairo, Egypt

7. WHO Special Programme for Research and Training in Tropical Diseases (TDR), World Health Organization, Geneva, Switzerland

8. Social Determinants of Health Department, World Health Organization, Geneva, Switzerland

9. Facultad de Ciencias Médicas, Universidad Nacional Autónoma de Honduras (UNAH), Tegucigalpa, Honduras

10. Integrated Health Services Department, World Health Organization, Geneva, Switzerland

11. Centro Internacional de Entrenamiento e Investigaciones Médicas (CIDEIM), Colombia

12. Universidad Icesi, Cali, Colombia

13. College of Medicine, University of Philippines, Manila, Philippines

14. Department of Medicine, School of Health Sciences, University of Philippines, Manila, Philippines

15. Social Innovation in Health Initiative (SIHI), SIHI Hub, Nnamdi Azikiwe University, Awka, Nigeria

*. Corresponding author: Semeeh Akinwale Omoleke, Country Readiness and Strengthening Department, Health Emergencies Program, World Health Organization, Geneva, Switzerland. Email: omolekes@who.int. 
Cite this article: Omoleke, S.A., Bayugo, Y.V., Oyene, U.E., Abrahams, J., Gobat, N., Good, S., Manandhar, M., Elfeky, S., Hernandez Bonilla, A.G., Valentine, N., Alger, J., Huda, Q., Mustafa, S., Echavarria, M.I., Rakesh, A., Warren, T., Lapitan, J.M., Mier-Alpano, J.D., Spencer-Walters, D., Del Pilar Labarda, M., Mihut, M., Bhatiasevi, A., Ekwunife, O.I. The WHO Community Engagement Package: Strengthening an Inclusive Global Public Health Approach. Int J Epidemiol Health Sci 2021; 2(7):e16. Doi: 10.51757/IJEHS.2.7.2021.244835.

\begin{abstract}
Community Engagement (CE) plays a crucial role in successful public health actions, achieving universal health coverage, and the realization of the United Nations Sustainable Development Goals. It has emerged as an effective strategy across different settings through prevention, preparedness, readiness and response, and recovery towards attaining community resilience, Primary Health Care (PHC) strengthening and universal health coverage (UHC), health security, and sustainable development. We reviewed the existing literature and various data sources and found that several CE training packages are available from international partners, focusing on the principles, theories, general questions, and CE techniques. However, there are still challenges because they are often fragmented, with little or no systematic procedures to guide the CE processes in different settings. In this light, WHO initiated a discourse on the CE Package (CEP) development in consultation with some selected international partners. The CEP Project will focus on developing a database, learning, and workshop packages based on curation of CE experiences in different settings using defined criteria. The CEP would harmonize CE processes and facilitate the reinforcement of the CE integration into public health. Further, the CEP Project serves as a collection of selected best practices for pre-service and in-service training packages for health professionals. Also, there is an anticipated inclusion into curricula of health training institutions and WHO staff capacity development. Finally, the database for compiling best practices is designed such that it can be periodically updated and becomes a compendium of CE for learning, research, and informing practice.
\end{abstract}

Keywords: Community Engagement; Community Engagement Package; Global Public Health; Health Emergencies; Disaster Risk Management; Primary Health Care

\section{Background}

Community Engagement (CE) is critical to effective disease prevention, health promotion, health research and policy-making, health emergency and disaster risk management, and primary health care (PHC) delivery.(1,2) It has emerged as an effective strategy across different settings through prevention, preparedness, readiness and response, and recovery towards attaining community resilience, PHC strengthening and universal health coverage (UHC), health security, and sustainable development.(2-6)

$\mathrm{CE}$ has been defined in different ways. Central to these definitions is the notion of involvement of community members, community leaders and influencers, patients, health professionals, policy-makers, and the private sector. These relationships should be characterized by mutual respect, trust, and a sense of purpose regarding health-related issues at stake, including public health risks and events.(2) The World Health Organization (WHO) defines Community Engagement as a process of developing relationships that enable stakeholders to work together to identify and address health-related issues, and promote wellbeing to achieve positive health impact and outcomes.(2) CE in health and social development sectors pre-dated the 2014-2016 Ebola Virus Disease
(EVD) outbreaks in West Africa. However, CE has received more attention after the 2014-2016 outbreaks in West Africa. For example, the experience triggered a workshop commissioned by WHO in Africa to document the lessons learned during the outbreak. ${ }^{(2)}$ In this light, the United States Centers for Disease Control and Prevention defined $\mathrm{CE}$ as "the process of working collaboratively with and through groups of people affiliated by geographic proximity, special interest, or similar situations to address issues affecting the well-being of those people".(7)

For addressing the interests of communities, community engagement has to be very closely associated with civil society action, where civil society is defined as "the arena of uncoerced collective action around shared interests, purposes and values".(8) "Civil society commonly embraces a diversity of spaces, actors and institutional forms, varying in their degree of formality, autonomy, and power. Civil societies are often populated by organizations such as registered charities, development non-governmental organizations, community groups, women's organizations, faith-based organizations, professional associations, trade unions, self-help groups, social movements, business associations, coalitions and advocacy groups".(8) These are all key stakeholders in the communities and are potentially relevant in 
building consensus, supporting community readiness and resilience against disasters and emergencies, postdisaster rehabilitation and social development and economic empowerment of the local communities. The concepts of "community engagement" and "civil society engagement" are not new. Community participation was considered the bedrock of PHC in the Alma Ata Declaration of 1978 and had paved the way for community participation, community engagement, and mobilization in health.(9) This notion related to "civil society engagement" was central to the work of the WHO Global Commission on Social Determinants of Health. The WHO Commission's final report recommendations were: to empower all groups in society through fair representation in decision-making about how society operates, particularly in relation to its effect on health equity; and to enable civil society to organize and act in a manner that promotes and realizes the political and social rights affecting health equity.(10)

This notion was revived as "engagement and empowerment" and became a core strategy of the WHO Framework on integrated people-centered health services (IPCHS) adopted by the Member States in 2016 and forms part of the global accelerators for the Sustainable Development Goals $(11,12)$. Therefore, CE is foundational to public health. Though the background of this paper draws more from emergency-related contexts, however, there are many other examples in other aspects of public health and non-health sectors, such as rural and urban development and agriculture. Indeed, CE strategy had been applied to numerous health and social developmental issues.(13-16) However, the importance of $\mathrm{CE}$ was particularly more vivid and reinforced during events associated with natural and technological hazards, conflicts, epidemics, and currently with the ongoing COVID-19 pandemic.(4,17-19) The lessons from previous emergencies and disasters, such as Severe Acute Respiratory Syndrome (SARS) in China, EVD in West Africa and Democratic Republic of Congo (DRC), Zika Virus Disease Outbreak in Latin America and the Caribbean, Tsunami in Thailand, Great Eastern Japan Earthquakes and the Fukushima Daiichi nuclear accident in Japan, and the ongoing COVID-19 pandemic underscore the significance of $\mathrm{CE}$ for the success of responses, including health interventions, irrespective of the diverse context and drivers of the emergency. The evidence from the experiences should be adequately-documented in a repository and made widely available to inform global health and development strategies.

One of the many lessons learned from emergency risk management, including preparedness, readiness, and response, is the consequence of a low community participation level. For example, at the start of the EVD outbreaks in West Africa and the DRC,- a price was paid when policy decision-makers and implementers failed to be inclusive in designing and implementing interventions for local populations.(18,20) At the outset of the EVD epidemic, voices that advocated a more informed and intensive community-involvement in prevention, surveillance, care of the sick, and rehabilitation of survivors and families of the sick were inadequately communicated. However, at that early phase, these community-centered views were not adopted by both State and non-State actors involved in the EVD response. Learning from the experience and available evidence, the inclusion of community views and voices to develop public health measures that account for people's contextual and day-to-day realities will more likely produce interventions that work.

Given the different contexts in which disease outbreaks, natural hazard-related disasters, and humanitarian crises occur and the dynamics over time, different $\mathrm{CE}$ strategies are required for prevention, preparedness, readiness, response, and recovery.(2025) Further, the non-availability of vaccines against EVD in 2014 in West Africa and the protracted period of disease transmission left national public health authorities and local actors to rely heavily on public health and social measures (PHSM) as a primary prevention and control tool. Similarly, for COVID-19, many countries have implemented mask-wearing, a ban on social and religious gatherings, restrictions on travels, stay-at-home orders, and the imposition of curfew measures, though with varying degrees of compliance and success.(26) However, the effectiveness of these measures depends on a common understanding of disease transmission mechanism (communities' perspectives), level of engagement with the communities, and contextual factors. For example, the International Association of Public Participations defines different levels of engagement, including inform, consult, involve, collaborate, and empower.(27) Evidence from health generally, and now COVID-19 pandemic, shows that informing communities achieves far fewer results than collaborating and empowering. Also, the context of trust in government and healthcare workers is also key for advancing actions in times of COVID-19 pandemic response.(28)

Government decision-makers and health workers work in hierarchical structures that often hinder understanding of real-world dynamics and make responsiveness often lagged. There is also the notion that with the hierarchy, there is an authority over civil society rather than working "for" communities. 
Therefore, individuals and communities' perspectives must be consciously addressed when new developments emerge for preventive and control measures.(26) However, the willingness and conviction could depend on public perception, public trust, ethnography, self-efficacy, sense of discipline and duty to the society, and economic context. $(29,30)$ For example, adopting social and physical distancing and lockdown measures appears challenging across many settings, especially in developing countries of Africa, and was on occasions implemented with the deployment of security services leading to civilians' deaths.(31,32) Such coercive measures are short-lived and unsustainable and often widen the trust gap between the government or policy-makers and the communities.

An incident in Malawi brought to life the role of the economic context, public risk perception, and human rights perspective in the ongoing COVID-19 pandemic response. The COVID-19 lockdown was opposed under the argument that most Malawians live on less than one US\$ per day and cannot afford to purchase necessities for 21 days at once.(33) This prompted the civil rights group, Human Rights Defenders Coalition (HRDC) to obtain a court injunction on the proposed lockdown, arguing that more consultation was needed to prevent harm to the poorest and most vulnerable in the society.(33) Besides the emergence of variants of SARS-CoV-2 that appears more infectious,(34-36) the observed asymmetry and power imbalances (often dictated by level of education, ethnicity, state institutional and political structure), "top-bottom" approach and trust gap between the political leaders, policy-makers and the communities may partly explain the sustained transmission and the intensity of the second wave of the COVID-19 outbreak in parts of Africa, Latin America, Western Europe, and the United States of America.

Even with the roll-out of vaccines under the emergency use authorization program of WHO, vaccine confidence is a challenge in many settings, and continued mass implementation of PHSM remains relevant until the COVID-19 pandemic ends. Therefore, overcoming the barrier of failure of confidence for achieving a successful vaccine roll-out will be aided by ensuring effective $\mathrm{CE}$ to build trust and confidence for local vaccine acceptability and overcome cultural, socioeconomic, and political barriers that hinder vaccine uptake $(37,38)$ and other medical and social countermeasures. Community engagement is also important in defining equity in priorities for roll-out, alongside medical criteria. These discussions early on in vaccine planning, while being democratic, can reinforce the acceptability of new vaccines. These experiences, scenarios, and potential challenges further underscore the importance of community engagement and social science research in providing a better understanding of the various contexts and, thus, guide the gauging and application of relevant and contextually-acceptable public health and social measures, including mass vaccination against COVID-19.

The COVID-19 pandemic has placed an unprecedented burden on health systems and the healthcare workforce, especially in communities with limited resources and inadequate access to basic healthcare. $(39,40)$ Control efforts to reduce the impact of the pandemic require social action from individuals and communities. The local community leaders, civil societies, and private sector should be engaged in an integrated risk management approach - a feature of a resilient health system, as their involvement brings complementary and crucial perspectives. $(3,22,41)$ Therefore, communities and their structures should be an integral part of the overall response management and not a mere recipient of health services and public health response efforts. The perspectives of the communities should be reflected when developing policies and interventions on how best to maintain essential and routine health services while preventing, preparing, and responding to pandemics and other hazards. This agrees with the position advocated by the WHO Director-General at the early phase of the COVID-19 pandemic, i.e., the "whole-of-society", "whole-of-government" approaches to prevent infections, save lives and minimize impacts.(42)

In many settings, there are existing structures at the community level established by past and current programs implemented at the PHC level, which are not fully tapped for health emergencies and other health needs. The capacity to reap the potential resiliencedividend is hampered by low adaptability given the verticalization of such donor-driven programs in lowand-middle-income countries (LMICs).(43) Often, donor-driven health projects and humanitarian responses have a short life-span leaving vestiges of benefits to the health system and the larger society. Studies of our existing field experience have shown that many of these donor and government-driven interventions employ "top-down" approach, have specific and narrow objectives with a limited bearing on health system strengthening. Conceptually, the PHC system promotes community-led initiatives and community-centered delivery of healthcare services for all. $(43,44)$ This builds trust and strengthens ties between the peripheral health services and the local communities. The proponents of community engagement and people-centered public health intervention recommended that relevant community 
leadership structures and actors should be involved right from program inception. $(2,4)$ For example, the perspectives of communities should be considered when developing policies and public health action to maintain essential and routine health services during pandemics, disasters, or humanitarian crises. Hence, the community should be an equal partner; local resources are identified, and consensus is reached on the role and responsibilities of all partners (i.e., communities, health services, local and international partners including non-governmental organizations (NGOs), and private sector) involved in planning, preparedness and readiness, implementation, monitoring, and reporting. $(32,43,44)$ However, these engagement models note that unequal power between for-profit private sector interests needs to be managed appropriately to serve the needs of the most disadvantaged and address power and resource imbalances. The communities can collaborate with external partners to develop culturally-appropriate programs that meet their felt needs. $(2,4)$ Therefore, there is a need for an appropriate CE strategy to support all-hazards health emergency and disaster risk management efforts. Such community-led or community-supported social actions were demonstrated in contact tracing and surveillance for EVD response in West Africa in 2014-2016 and DRC in 2018-2019, and other humanitarian settings.(21,32, 45) Further, Community Directed Interventions (CDI) have also been used to launch highly successful health programs and disaster management in sub-Saharan Africa and South Asia, such as the river blindness control program, dengue vector breeding control, malaria control, including home-based management of malaria, maternal and child health, distribution of health commodities (such as Vitamin A), and disaster risk reduction and community-based management in Nigeria, Uganda, Tanzania, Myanmar and Bangladesh.(46-49)

A national multidisciplinary approach had been advocated, learning from the EVD outbreak in DRC and other disaster and humanitarian crises settings, to institute an interactive consultation framework between the communities, local leaders, and other actors involved in the response.(50) National public health institutes or agencies with local authorities may be the natural place to institute and sustain these consultative mechanisms, permeating through the entire health systems and response structures. More community-led approaches should be explored and adapted to build a culture of involving communities in strengthening health systems and disaster risk management and building long-term resilience to address challenges posed by the current COVID-19 pandemic, disaster risks associated with natural and technological hazards, and the risk of future pandemics.(4) These lessons paved the way for developing strategies and protocols for social mobilization and $\mathrm{CE}$ by risk communication and community engagement (RCCE) partners, such as WHO, Global Outbreak Alert and Response Network (GOARN), International Federation of Red Cross and Red Crescent (IFRC), United Nations Children's Fund (UNICEF).

\section{WHO Community Engagement Package}

WHO's 13 ${ }^{\text {th }}$ General Program of Work (GPW13) goals align with the Sustainable Development Goals 2030 (SDG 2030), wherein 169 UN Member States agreed to work towards achieving these goals by the year 2030.(51) There are 17 SDGs, and SDG 3 focuses on health.(52) The Global Action Plan for Healthy Lives and Well-being for All (SDG3) identifies community and civil society engagement as one of the seven themes for which specific actions in the country, global and regional levels need to be reinforced.(52) Therefore, the WHO-led CEP package aims to strengthen existing gains, ensures that all the sectors of the society and the government are actively involved in the disaster risk management, readiness, prevention and control of epidemics and pandemics, and maintaining the health and well-being of the people outside the crisis period in countries worldwide.

Several CE training packages are available from international partners, focusing on the principles, theories, general questions, and $\mathrm{CE}$ techniques. $(2,4,53)$ However, there are still challenges because they are often fragmented, with no systematic procedures and structures to guide the $\mathrm{CE}$ processes in different settings. Further, there is a diverse understanding of the concept of community participation in strengthening health programming and the application of different protocols. The WHO CE package will focus on $\mathrm{CE}$ experiences in specific settings and contexts and use the existing materials as resources for a basic introduction to $\mathrm{CE}$. Further, there is no robust repository with a set-criteria for a systematic collection and inclusion of various best practices that have been employed in different settings and contexts in countries across the six regional offices of WHO. Besides, there is a need to update such best practices periodically, given the contextual and environmental dynamics of public health, humanitarian, and disease outbreak situations across the globe.

Based on the above (gaps and importance of CE), the Country Readiness Strengthening Department initiated discussions with relevant departments at the 
WHO Headquarters (HQ) and interested WHO colleagues (Community of Practice) from all the WHO Regional Offices and Global Outbreak Alert and Response Network (such as UNICEF, IFRC) to draw on their experiences working and engaging with communities in different contexts and settings. Hence, the WHO Community Engagement Project (CEP) sets out to develop a database of $\mathrm{CE}$ experiences in different settings and develop a CE learning package based on the repository (database) of experiences in various settings. The CEP will also develop a CE workshop package based on curation of $\mathrm{CE}$ experiences in different environments. The learning package will be an online interactive format on a short topic targeting a diverse audience. Initially, most of the existing $\mathrm{CE}$ training packages cover community engagement basics - what, why, when, how, tips, etc. These materials would be referred to as prerequisites/basic modules before taking the $\mathrm{CE}$ learning package.

The workshop package is different from the learning package as it aims to provide tools/templates in generating and identifying other $\mathrm{CE}$ experiences in a workshop format. These resources will be cataloged, categorized, and included in the $\mathrm{CE}$ experiences database.

\section{How to Achieve the Novel Initiative?}

As a first step, the WHO has shored up its capacity to work in this area by establishing a Memorandum of Understanding with Social Innovation in Health Initiative (SIHI), Philippines, to further this work. The CE package will be developed in collaboration with the SIHI whose secretariat is hosted at the University of Philippines, Manila. SIHI is a global network of partners advancing social innovation in health through research, capacity building, and advocacy. The SIHI network and its various country hubs have a proven experience and capacity to achieve the project's objectives. Further details about SIHI and its network in different parts of the world can be found on the website at https://socialinnovationinhealth.org/. For this project, the SIHI Philippines will be working along with SIHI hubs in Malawi, Nigeria, South Africa, Columbia, and Honduras.

The WHO will oversee the work, ensuring the deliverables (outputs) within the project's scope are achieved over six months. In coordination with WHO staff, SIHI hubs will be mobilized to gather studies, grey literature, and unpublished CE cases. Specific criteria will be developed to ensure that a minimum quality evaluation of the cases is undertaken. They shall also write case abstracts about the experiences that have been identified. SIHI Philippines will coordinate the collection of cases around the world. The collected materials will be organized and analyzed, and community engagement concepts that will surface will be used to guide the development of a CE learning package. Virtual meetings between SIHI hubs will be held to further develop the content of the learning package. The prototype online learning package will be developed in the Philippines (SIHI Secretariat). Pilot testing of the prototype packages will be done initially in the Philippines. A subsequent pilot test will be done with participants in another country where a SIHI hub is based. Consultative sessions among key stakeholders will be done to elicit relevant feedback and revise the training materials and package accordingly. The final version of the learning package will be developed by SIHI Philippines in consultation with concerned offices of WHO and the SIHI community engagement specialists.

\section{Search for Relevant Literature and Materials}

A search of materials that captured or documented CE experiences in health programs and interventions will be conducted. This will include the work of WHO and its partners as well as other key community stakeholders. The search shall be conducted through available online platforms, websites of organizations recognized for $\mathrm{CE}$, and grey literature. We also include the inclusion criteria we will use for the selection of relevant materials. The inclusion criteria for the search are documentation in reputable sources or sources that can provide adequate information/documentation for the assessment of validity and articles published in the last ten years or undocumented experiences active within the last ten years. Lastly, all CE criteria are met:

- Captures or documents experience on community engagement addressing a health need or social determinant of health

- Uses a participatory approach and active two-way communication using language appropriate for different actors and stakeholders

- Encourages collaboration or synergies and sharing of expertise with various stakeholders and sectors especially, but not limited to, marginalized groups to improve capacities

- Involves community in the different phases of implementation 
$\circ$ of the intervention or strategy, such as planning, context analysis, decision making, research, monitoring, evaluation, and/or learning to ensure inclusive representation, maximum participation, and uncompromised consultation

- Builds and sustains trust with the community

A WHO focal person and the CEP team will also provide sources and contacts that contain relevant materials for the project. Materials to be included are news and feature articles, videos, books, magazines, newsletters, scientific journal articles, technical reports, databases, and webpages. Interviews and correspondences with key informants shall also be conducted for undocumented CE practices. These interviews will be undertaken in coordination with the WHO team and the RCCE working group. In addition, case reports shall be compiled for each of the identified experiences. These experiences will then be packaged into learning and workshop resources in narratives and case studies highlighting the approaches, methodologies, and critical lessons.

There are a number of definitions for community and community engagement. For this piece of work, "community" will be defined as a group of people who are affected by the health issues being addressed. The operational definition for this work of community engagement may be revisited after the literature review but, at the outset, it is based on the adapted WHO definition as follows: CE is a process of reconnecting with people being served, their needs, understanding, and contexts through developing relationships that empower those impacted, thereby enabling stakeholders to work together to address health-related issues and promote well-being to achieve positive health, and health equity impacts and outcomes.(2)

\section{CEP Project Deliverables}

These three key deliverables have some outputs and are outlined below:

Deliverable 1: Developing a database of experiences on community engagement across public health in different settings.

- Together with the WHO regions and GOARN and relevant partners in identifying relevant resources that capture community engagement experiences, including criteria for selecting cases to be presented in the learning and workshop packages

- Compile documents, videos, and other available formats and highlighting the experiences-lessons and challenges in working with the communities by the WHO and relevant partners. The documents and materials can be in English, Spanish, and French. A summary or abstract in English will be provided in all the documents

- Conduct interviews on practices/experiences that were not formally documented- this is notably the case in communities

- Organize and categorize the documents as references in developing learning and workshop resources on community engagement

- Support dissemination to institutions and relevant networks

Deliverable 2: Develop a community engagement learning package based on Deliverable 1.

- Identify and list existing community engagement packages from WHO and partners.

- Develop a framework/matrix in the organization of the learning package (as to setting or context, target audience, technical topics)

- Develop a training prototype for testing (using Rise or other relevant interactive format)

- Finalize the package, including evaluation

- Support dissemination to institutions and relevant networks

Deliverable 3: Develop a community engagement workshop package based on Deliverable 1.

- Identify and assemble different methodologies to be used in the workshop

- Develop tools and template to generate and identify experiences in community engagement across public health in different settings and contexts, including cataloguing and categorizing these experiences for inclusion in the database

- Draft a workshop package (develop a framework/matrix to organize the learning package, e.g., as to setting or context, target audience, technical topics) both available for virtual learning and downloadable formats 
- Ensure mechanism to facilitate newly identified best practices gets incorporated in the CE repository

- Support dissemination to institutions and relevant networks

\section{Limitations}

One of the limitations of this project is the restriction to materials written in languages other than English, French, and Spanish. However, a substantial proportion of cases would have been covered with these widely used languages, i.e., English, French, and Spanish. Also, there is a possibility of missing some undocumented experiences that fit the set criteria, given the limitation of SIHI networks and the restriction to travel during the COVID-19 pandemic. This is, however, being mitigated through the use of information technology tools to access key informants who could share such undocumented experiences.

\section{Conclusion}

The CEP concept is based on consultations with the WHO colleagues and partners working on $\mathrm{CE}$, and co-creation by CE experts from WHO, RCCE Collective Service, CE practitioners, academics, representatives of civil society and vulnerable populations.. The CEP leverages the existing resources and works done on CE over the past years, and the package will advance the CE process, structure, and its organizations. It will provide lessons and procedures in engaging the communities in various contexts and could strengthen the integration of CE into public health and WHO and GOARN partners' work areas. The WHO CE Learning Package provides structured learning opportunities for public health practitioners, especially those who are members of a community of practice or interface with the communities, civil societies, faith and communitybased organizations, and the local private sector. The CEP is a compilation of best practices in community engagement to be made available for $\mathrm{CE}$ practitioners, pre-service training of future public health professionals and for WHO staff capacity development. Standard credits can be earned, and certificates may be provided to individuals who complete all the required modules. It could also be part of courses to attain a degree or diploma in health and health-related disciplines and a component of the inservice training package for health professionals. However, this would require strong advocacy, relevant UN agencies' involvement, and high-level political commitment. A database for archiving best practices and learning experiences would be developed and periodically updated and thus become an encyclopedia of CEP for research and reference purposes. A userfriendly workshop package for training and orientation in different UN languages would be developed and could be adapted for use at various operational levels across countries and regions.

Community Engagement (CE) is crucial to public health actions, attainment of universal health coverage, and the realization of the United Nations Sustainable Development Goals, even beyond goal three (3) that directly impact population health and well-being. Beyond the immediate and short-term gains of $\mathrm{CE}$ in its various forms, it could facilitate the community health systems' sustainability, and resilience as the public health actions or measures are co-created, co-owned, and supported by the local communities. CE is very relevant in LMICs and disadvantaged populations in high-income countries (HICs), ensuring that no one is left behind.

Author's contribution: SAO and YVB conceived the idea of the manuscript, SAO designed the framework and wrote the first draft of the manuscript. SAO, YVB, and UEO conducted a literature search. SAO, YVB, UEO, JA, NG, SG, MM, SE, AGHB, NV, JA, QH, SM, MIE, AR, TW, JML, JDMA, DSW, ML, MM, $\mathrm{AB}, \&$ OIE reviewed and edited the manuscript drafts. All the authors read, validated, and approved the final draft of the manuscript before submission for publication.

Acknowledgment: The authors acknowledged the support of all the Community Engagement Working Group members who were consulted at the conceptualization of the Community Engagement Package Project. We shall also appreciate the critical comments from the TDR colleagues- Drs Abraham Aseffa and Beatrice Halpaap, during the manuscript preparation.

Declaration of Interest: The authors do not have any conflicting interests.

\section{References}

1. Health emergency and disaster risk management framework. 2019. Available from:

https://apps.who.int/iris/handle/10665/32610 6.

2. WHO. WHO Community Engagement Framework for Quality, People-centred and Resilient Health Services. 2017;56. Available from: http://apps.who.int/bookorders. 
3. Olu, O., Drameh-Avognon, P., Asamoah-Odei, E., Kasolo, F., Valdez, T., Kabaniha, G., et al. Community participation and private sector engagement are fundamental to achieving universal health coverage and health security in Africa: Reflections from the second Africa health forum. BMC Proc. 2019;13(Suppl 9):111.

4. International Federation of Red Cross and Red Crescent Societies. From words to action : Towards a community-centred approach to preparedness and response in health emergencies. 2019. Available from: https://apps.who.int/gpmb/thematic_report.ht $\mathrm{ml}$.

5. Secretary-general UND, Force TT. Global Health Crises Task Force Final Report. 2017;122. Available from: https://www.un.org/en/our-work/globalhealth-crises-task-force.

6. World Health Organization. WHO DirectorGeneral's keynote speech at the St Petersburg International Economic Forum '21. WHO. 2021. Available from: https://www.who.int/directorgeneral/speeches/detail/who-director-generals-keynote-speech-at-the-st-petersburginternational-economic-forum-21.

7. Department of Health and Human Service, USA: Committee $C$ and TSA (CTSA) CCEKF. Principles of Community Engagement. NIH Publ No 11-7782. 2011; http: //www.cdc.gov/ phppo/pce/. Available from: http://www.atsdr.cdc.gov/communityengagem ent/pdf/PCE_Report_508_Final.pdf.

8. Commission on Social Determinants of Health WHO (WHO). Civil Society Report Civil Society Report. WHO. 2007. Available from: https://www.who.int/social_determinants/reso urces/cso_finalreport_2007.pdf?ua=1.

9. Alma-Ata Declaration. In: International Conference on Primary Health Care. Alma-Ata, USSR (Now Kazakhstan); 1978. p. 6-8. Available from: https://www.who.int/publications/almaata_dec laration_en.pdf.

10. Gama e Colombo, D. Closing the gap in a generation: health equity through action on the social determinants of health. Final report of the Commission on Social Determinants of Health. Rev Direito Sanitário. 2010;10(3):253.

11. WHO. Interim report: placing people and communities at the centre of health services: WHO global strategy on integrated peoplecentred health services 2016-2026: executive summary. Geneva, Switzerland: World Health Organization; 2015 Jul. Available from: https://apps.who.int/iris/handle/10665/180984.

12. UNAIDS and WHO. Consultation with NonState Actors on GAP and its 'Accelerators' on Community \& Civil Society Engagement, Determinants of Health and Primary Health Care. New York; 2019 Apr. Available from: https://www.who.int/docs/default-

source/global-action-plan/meeting-report-nsaconsultation-on-gap-april-

2019.pdf?sfvrsn=f3f87c54_2.

13. Milton, B., Attree, P., French, B., Povall, S., Whitehead, M., Popay, J. The impact of community engagement on health and social outcomes: a systematic review. Community Dev J. 2012;47(3):316-34.

14. Wells, K.B., Tangm J, Lizaolam E., Jones, F., Brown, A., Stayton, A., et al. Applying community engagement to disaster planning: Developing the vision and design for the Los Angeles county community disaster resilience initiative. Am J Public Health. 2013;103(7):1172-80.

15. Cairncross, S., Braide, E.I., Bugri, S.Z. Community participation in the eradication of guinea worm disease. Acta Trop. 1996;61(2):121-36.

16. Nasir, S.G., Aliyu, G., Ya'U, I., Gadanya, M., Mohammad, M., Zubair, M. et al. From intense rejection to advocacy: How muslim clerics were engaged in a polio eradication initiative in northern nigeria. PLoS Med. 2014;11(8):1-6.

17. World Health Organization. Health Emergency and Disaster Risk Management: Overview. Health Emergency and Disaster Risk Management Fact Sheets. 2019. Available from:

https://www.who.int/hac/techguidance/prepare dness/health-emergency-and-disaster-riskmanagement-framework-eng.pdf?ua=1.

18. Ilunga Kalenga, O., Moeti, M., Sparrow, A., Nguyen, V.K., Lucey, D., Ghebreyesus, T.A. The Ongoing Ebola Epidemic in the Democratic Republic of Congo, 2018-2019. N Engl J Med. 2019;381(4):373-83.

19. Bedson, J., Jalloh, M.F., Pedi, D., Bah, S., Owen, K., Oniba, A., et al. Community engagement in outbreak response: Lessons from the 2014-2016 Ebola outbreak in Sierra Leone. BMJ Glob Heal. 2020;5(8):1-12. 
20. Omoleke, S.A., Mohammed, I., Saidu, Y. Ebola viral disease in West Africa: A threat to global health, economy and political stability. J Public Health Africa. 2016;7(1).

21. Gilmore, B., Ndejjo, R., Tchetchia, A., De Claro, V., Mago, E., Diallo, A.A., et al. Community engagement for COVID-19 prevention and control: A rapid evidence synthesis. BMJ Glob Heal. 2020;5(10):1-11.

22. Barker, K.M., Ling, E.J., Fallah, M., Vandebogert, B., Kodl, Y., Macauley, R.J., et al. Community engagement for health system resilience: Evidence from Liberia's Ebola epidemic. Health Policy Plan. 2020;35(4):416-23.

23. Marston, C., Renedo, A., Miles, S. Community participation is crucial in a pandemic. Lancet 2020;395(10238):1676-8.

24. Gillespie, A., Obregon, R., El Asawi, R., Richey, C., Manoncourt, E., Joshi, K., et al. Social mobilization and community engagement central to the Ebola response in West Africa: Lessons for future public health emergencies. Glob Heal Sci Pract. 2016;4(4):626-46.

25. National Research Council. Facing Hazards and Disasters: Understanding Human Dimensions. Facing Hazards and Disasters. Washington, DC.: The National Academies Press; 2006. Available from: https://www.loc.gov/item/2006931516.

26. Partnership for Evidence-Based Response to COVID-19 (PERC). Responding to COVID19 in Africa- Using Data to Find a Balance. PERC Report. 2020. Available from: https://preventepidemics.org/covid19/perc.

27. Glenorchy City Council. Community Engagement Procedure. 2017. Available from:

https://letstalk.gcc.tas.gov.au/62601/widgets/ 314486/documents/185092.

28. Shadmi, E., Chen, Y., Dourado, I., FaranPerach, I., Furler, J., Hangoma, P. et al. Health equity and COVID-19: global perspectives. Int J Equity Health. 2020;19(1):104.

29. Nuriddin, A., Jalloh, M.F., Meyer, E., Bunnell, R., Bio, F.A., Jalloh, M.B. et al. Trust, fear, stigma and disruptions: Community perceptions and experiences during periods of low but ongoing transmission of Ebola virus disease in Sierra Leone, 2015. BMJ Glob Health 2018;3(2):111.

30. Van Bortel, T., Basnayake, A., Wurie, F., Jambai, M., Koroma, A.S., Muana, A.T. et al.
Psychosocial effects of an Ebola outbreak at individual, community and international levels. Bull World Health Organ. 2016;94(3):210-4.

31. Yaya, S., Out, A., Labonté, R. Globalisation in the time of COVID-19: Repositioning Africa to meet the immediate and remote challenges. Global Health. 2020;16(1):1-7.

32. Anoko, J.N., Barry, B.R., Boiro, H., Diallo, B., Diallo, A.B., Belizaire, M.R. et al. Community engagement for successful COVID-19 pandemic response: 10 lessons from Ebola outbreak responses in Africa. BMJ Global Health 2020;4:1-4.

33. Phiri, F. Malawi high court sets aside coronavirus lockdown pending review. Reuters. 2020 Apr 17; Available from: https://www.reuters.com/article/us-healthcoronavirus-malawi-idUSKBN21Z319.

34. Public Health England. Investigation of novel SARS-CoV-2 variant Variant of Concern 202012 / 01 Technical briefing 2: Nomenclature of variants in the UK Current epidemiological findings. 2020;1-12. Available from: https://assets.publishing.service.gov.uk/gover nment/uploads/system/uploads/attachment_d ata/file/959361/Technical_Briefing_VOC202 012-2_Briefing_2.pdf.

35. Wise, J. Covid-19: New coronavirus variant is identified in UK. BMJ. 2020;371:m4857.

36. Tang, J.W., Toovey, O.T.R., Harvey, K.N., Hui, D.D.S. Introduction of the South African SARS-CoV-2 variant 501Y.V2 into the UK. J Infect 2021;82(4):e8-e10.

37. Burgess, R.A., Osborne, R.H., Yongabi, K.A., Greenhalgh, T., Gurdasani, D., Kang, G. et al. The COVID-19 vaccines rush: participatory community engagement matters more than ever. Lancet. 2021;397(10268):8-10.

38. Lazarus, J.V., Ratzan, S.C., Palayew, A., Gostin, L.O., Larson, H.J., Rabin, K. et al. A global survey of potential acceptance of a COVID-19 vaccine. Nat Med. 2021;27:225228.

39. Nepomnyashchiy, L., Dahn, B., Saykpah, R., Raghavan, M. COVID-19: Africa needs unprecedented attention to strengthen community health systems. Lancet 2020;396(10245):150-2.

40. Khalid, A., Ali, S. COVID-19 and its Challenges for the Healthcare System in Pakistan. Asian Bioeth Rev 2020;12(4):55164. 
41. Kruk, M.E., Myers, M., Varpilah, S.T., Dahn, B.T. What is a resilient health system? Lessons from Ebola. Lancet 2015;385(9980):1910-2.

42. World Health Orgnization. Everyone's business: whole-of-society action to manage health risks and reduce socio-economic impacts of emergencies and disasters: operational guidance. 2020. Available from: https://apps.who.int/iris/handle/10665/33942 1.

43. White, F. Primary health care and public health: Foundations of universal health systems. Med Princ Pract 2015;24(2):103-16.

44. World Health Organization, United Nations Children's Fund. A vision for Primary health care in the 21st Century. World Heal Organ. 2018. Available from: https://www.who.int/docs/defaultsource/primary-health/vision.pdf.

45. IFRC, UNCEF W. preparedness \& response: Risk Communication and Action Plan Guidance. Unicef. Available from: https://www.unicef.org/media/65936/file/Pre paredness for and response to coronavirus 2019 (COVID-19).pdf.

46. Kisinza, W.N., Kisoka, W.J., Mutalemwa, P.P., Njau, J., Tenu, F., Nkya, T., Kilima, S.P., Magesa, S.M. A community directed interventions for malaria, tuberculosis and vitamin A in onchocerciasis endemic districts of Tanzania. Tanzan J Health Res 2008;10(4):232-9.

47. Ndjomugyenyi, R., Tukesiga, E., Katamanywa, J. Intermittent preventive treatment of malaria in pregnancy (IPTp): participation of community-directed distributors of ivermectin for onchocerciasis improves IPTp access in Ugandan rural communities. Trans R Soc Trop Med Hyg 2009;103(12):1221-8.

48. Okeibunor, J.C., Orji, B.C, Brieger. W, Ishola. G, Otolorin. E, Rawlins, B. et al. Preventing malaria in pregnancy through community-directed interventions: Evidence from Akwa Ibom State, Nigeria. Malar J. 2011;10(1):227.

49. Azad, M.A.K., Uddin, M.S., Zaman, S., Ashraf, M.A. Community-based Disaster Management and Its Salient Features: A Policy Approach to People-centred Risk Reduction in Bangladesh. Asia Pac J Rural Dev 2020;29(2):135-60.

50. Ntumba, H.C.K., Bompangue, D., Situakibanza, H., Tamfum, J.J.M., Ozer, P.
Ebola response and community engagement: how to build a bridge? Lancet 2019;394(10216):2242.

51. Office W-WPR. WHO GPW13 Impact Measurement. WHO. 2019. Available from: https://www.who.int/about/what-wedo/thirteenth-general-programme-of-work2019---2023.

52. Nations U. Transforming our world: the 2030 agenda for sustainable development. United Nations Sustainable Development Goals. 2016. Available from: https://sdgs.un.org/2030agenda.

53. Bedson,J., Abramowitz, S. Minimum Quality Standards and Indicators for Community Engagement. Unicef. 2018;1-2. Available from:

https://www.unicef.org/mena/media/8401/file /19218_MinimumQuality-

Report_v07_RC_002.pdf.pdf. 